\title{
Investigating the European energetic situation under a potential scenario that marginally meets Green Deal requirements
}

\author{
VASILIKI VITA, STAVROS LAZAROU \\ Department of Electrical and Electronic Engineering Educators \\ ASPETE - School of Pedagogical and Technological Education \\ N. Heraklion, 14121 Athens \\ GREECE
}

\begin{abstract}
The paper presents a potential energetic scenario that leads to near zero emissions for Europe in 2050, marginally meeting Green Deal requirements. Nevertheless, technologically wise it is an advanced implementation. It proposes a relatively high penetration of renewables (wind, solar, geothermal, biomass and nuclear), the increased use of electro-mobility, carbon capture and storage, hydrogen and other technologies. The simulations were performed using the open source Global Change Assessment Model (GCAM) and the simulation data and results are available online.
\end{abstract}

Key-Words: - Green Deal, Global Change Assessment Model (GCAM), Renewable Energy Sources, Electromobility, Renewable Energy Sources, Hydrogen.

Received: January 4, 2020. Revised: July 14, 2020. Re-revised: August 3, 2020. Accepted: August 14, 2020. Published: August 25, 2020.

\section{Introduction}

The Green Deal is the flagship initiative of the European Union for creating a carbon neutral continent up to 2050 [1]. It includes among other the provision of higher penetration for renewables, electrification of transport, energy efficiency and the improvement of industrial processes. This strategy will place the EU even more centrally to the global stage, but it will require the mobilization of a vast amount of resources from the public, as well as, the private sector. It will affect how the energy is produced, transmitted and delivered, how the buildings are built and how people are being transported. This will need to be achieved without leaving anyone of the citizens behind, offering equal opportunities to everyone. In order for the policy makers to be facilitated in their decisions for implementing Green Deal, researchers provide several scenarios on how several policy initiatives could be met.

Several open source integrated assessment models that are able to predict the future condition of the energy market, are available. This work is conducted using the Global Change Assessment Model (GCAM) [2, 3]. GCAM is a powerful, open source tool that uses the previous energetic condition of the system and projects it to the future. In order to interpret policy initiatives, several limitations and constraints are applied. The results are bulk amounts of data that require much attention to be properly understood. Several datasets produced from GCAM are not used in this analysis. These include for example calculations related to land use. Other sectors, except from the electricity, could contribute in mitigating the results of anthropogenic climate change, but here we only focus to the power system and the electrification of transport. The data used in this analysis were originally produced for the publication [4]. They are available online on Harvard Dataverse [5]. Okeanos cloud computing was used for the simulations [6]. This work is the continuation of a previous analysis on the subject [7]. The current findings show that there is at least one scenario at which the European energetic system is able to accommodate Green Deal.

\section{Integrated Assessment Models and their Capabilities}

Integrated Assessment Models are widely used for understanding how the energy systems on a national and global level shall evolve in the future. They inform a projection of the existing datasets onto the following years; taking into consideration several limitations, selected by the user. Predicting the future cannot ever be done accurately. The results are only ever indicative and they demonstrate general patterns rather than exact calculations. Policy makers are then enabled to take informed decisions. However, these decisions must also take into consideration a holistic understanding of societal, emerging and special 
events that are not adequately captured by these models.

The predominant reasoning behind selecting GCAM for this analysis was based on its open-source format. The $\mathrm{xml}$ simulation files and the insert data are made public by the developer and the results are available on Harvard Dataverse [5]. The scientific community is cordially invited to review the data and provide productive feedback for potential future improvement.

GCAM solver utilizes the input data to calculate a market equilibrium for each simulation step. Broyden method for non-linear equation systems $[2,3]$ is used to perform the arithmetic convergence. Every constraint is expressed using a non-linear equation:

$$
\begin{gathered}
f_{j}^{1}\left(x_{1}\right)=0 \\
f_{j}^{2}\left(x_{2}\right)=0 \\
f_{j}^{3}\left(x_{3}\right)=0 \\
\cdot \\
\cdot \\
f_{j}^{n-1}\left(x_{n-1}\right)=0 \\
f_{j}^{n}\left(x_{n}\right)=0
\end{gathered}
$$

Then for every solution it applies:

$$
\begin{gathered}
f_{j}^{1}(x)=0 \\
f_{j}^{2}(x)=0 \\
f_{j}^{3}(x)=0 \\
\cdot \\
\cdot \\
f_{j}^{n-1}(x)=0 \\
f_{j}^{n}(x)=0
\end{gathered}
$$

Each simulation step is expected to be somewhat different compared to the previous one.

$$
\begin{gathered}
B^{1}(x) \delta_{\chi}=-f^{1}(x) \\
B^{2}(x) \delta_{\chi}=-f^{2}(x) \\
B^{3}(x) \delta_{\chi}=-f^{3}(x) \\
\cdot \\
\cdot \\
B^{n-1}(x) \delta_{\chi}=-f^{n-1}(x)
\end{gathered}
$$

$$
B^{n}(x) \delta_{\chi}=-f^{n}(x)
$$

From the above, every new solution is not expected to be substantially different compared to the previous one, however, it shall be in the direction the inserted policy is directing.

\section{Scenario Penetration Findings}

The proposed scenario is an example that Green Deal requirements for achieving a carbon neutral Europe up to 2050. It is not by definition a one direction pathway and the needs of the strategy could be met using a wide selection of different tools and solutions that always revolve around renewables and carbon neural technologies. In this case it is given emphasis to the production from renewable energy sources including photovoltaics and wind. These technologies have very low impact to the environment. They are being developed rapidly and they increasingly have the unanimous social acceptance to be widely installed across the continent. They demonstrate several challenges to the power system, mostly due to their intermittency that needs to be mitigated by flexible production and storage [8]. However, these drawbacks are increasingly tackled due to the support provided by the European Union and the national governments. Attention is also given to nuclear production and to alternative solutions such as carbon capture and storage (CCS), as well as to the potential use of hydrogen [9]. Nuclear is carbon neutral and base load source of energy. It is able to provide important stability to the power system and it is geopolitically safe and secure, not affected by the price volatility of oil and gas. Nevertheless, issues of nuclear waste disposal and safety of operation create, to a certain degree, social strains for its wider application.

EU citizens quality of life is expected to further improve in time, maybe creating minor consumption increases. The population is also increasing. Based on the above, the current scenario shows minor total consumption increase across time that leads to 17582 EJ in 2050. In Fig. 1 can be observed that the energy consumption increase is almost steady across time. The measures to be taken in order to meet Green Deals requirements, need to take into consideration the future condition of the energy system. A sensitivity analysis could further improve the accuracy of the final results and facilitate policy makers in their decisions.

\subsection{Expected carbon emissions}

At this scenario total expected carbon emissions will substantially decrease; however, they will not reach the absolute zero. As provided at Fig. 2, according to 
the current scenario, at 2050 they will be around 100 MTC, which is much less than the current emissions. However, this amount remains distant from the expectation to become zero. This means that further measures have to be taken in order to achieve higher penetration of renewables and other zero emission resources, as well as, the enhanced application of energy efficiency initiatives across all sectors. At this point it is important to give emphasis to electromobility. The use of electric vehicles certainly provides advantages as far as emissions are concerned. It is contributing as well to the improvement of the overall quality of life in large cities. Dense smoke from old technology vehicles create respiratory problems. Electric vehicles are noise free and they need low maintenance further pushing down their total costs of ownership.

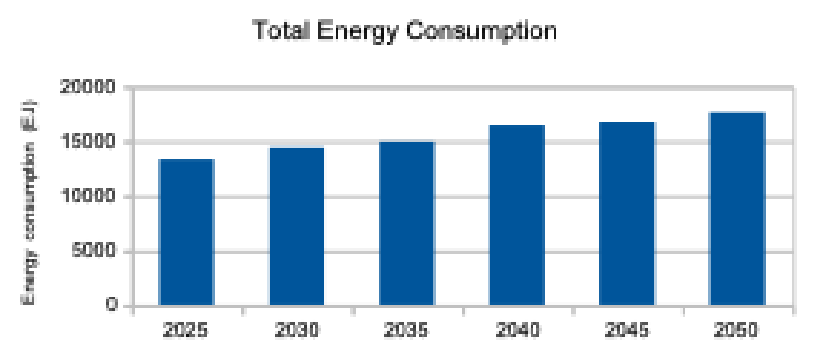

Figure 1: Total EU Energy Consumption.

The zero emissions target, unilaterally imposed by the European Union, could potentially strain energy intensive industrial production. This could be certainly the case; however, it will also create strong initiatives for improving the relevant technology, create more efficient production patterns and also provide the capability to export this knowledge to the rest of the world.

Energy consumption is expected to steadily increase across time, however, this in practice could be different. Energy efficiency measures substantially decrease the needs of energy. These energy efficiency measures include the improvement of buildings insulation, extensive use of combined heat and power, installation of heat pumps and more efficient heating systems.

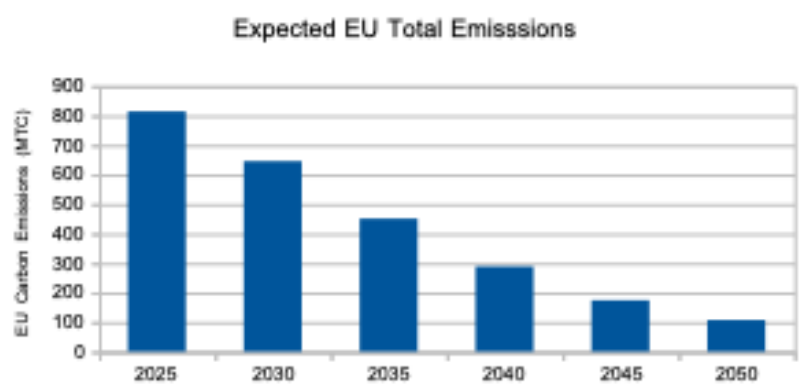

Figure 2: Expected EU Carbon Emissions.

\subsection{Production from zero carbon emission sources}

Fig. 3 depicts the expected penetration of onshore wind energy. It is observed that wind energy production steadily increases across time, gaining around $0.2 \mathrm{EJ}$ of production per calendar year. The technological evolvement of wind turbines, improves the yield of the existing sites and makes other ones, economically viable. Larger turbines are installed that are more able to harness the wind energy available across the continent and this trend is expected to continue in the following years [10]. It has to be mentioned, that this scenario remains a rather conservative one, at least as far as the penetration of wind power is concerned. Henceforth, Green Deal is expected to create even larger penetration of wind energy to the system.

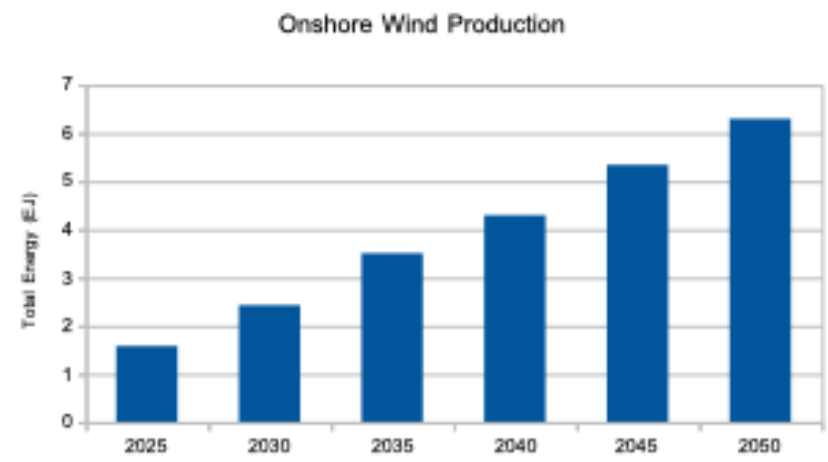

Figure 3: Onshore Wind Production across the EU.

On the other hand, as depicted to Fig. 4, solar production will increase in a higher rate across time. Photovoltaic prices have been already substantially decreased. This pattern is expected to continue for the following years. New regulations for zero energy buildings require the installation of rooftop solar systems. This will further boost solar energy production. In the current scenario solar penetration is relatively low. The photovoltaic potential of Europe, especially for the southern European countries is much larger. Moreover, photovoltaics in southern Europe demonstrate additional advantages for example the fact that they produce more at sunny day where energy is more needed by the system for cooling purposes.

Solar panels for the production of energy is an alternative to photovoltaics. They are not analysed in detail at this exercise because they require large areas with the appropriate climatic conditions to be installed, in comparison to photovoltaics that can be installed almost everywhere. Another important factor that it is not excessively analyzed in this work, is the use of solar panels for how water. In southern European countries this solution is widely used with 
very good results, pushing down the overall costs for heating from other sources of energy.

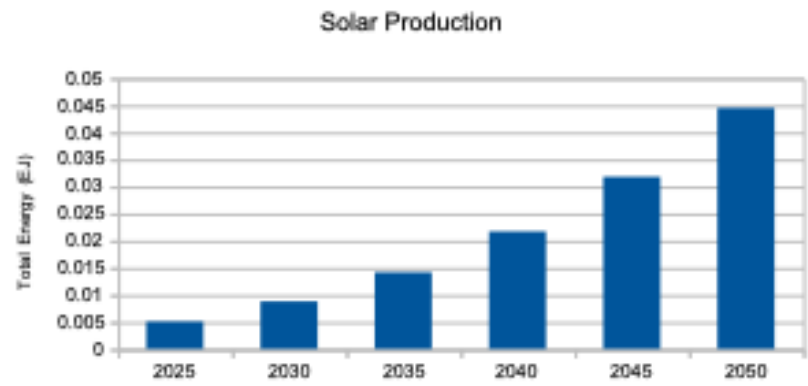

Figure 4: Solar Production across the EU.

Several initiatives, such as near to zero energy buildings and the new requirements for buildings require the installation of photovoltaic systems on the roof for urban buildings and possibly wind turbines for rural installations. As far as larger plants are concerned, regulatory authorities across the European Union issue continuously new licenses and the power systems are enhanced to accommodate higher penetration of solar energy.

In the current scenario, energy production from geothermal sources will soon achieve its maximum potential. As it is shown at Fig. 5 around 3EJ of energy will be produced from geothermal sources. Given that the necessary research and investigation to understand the geothermal potential across Europe is already done, this is a safe assumption. The amount of $3 \mathrm{EJ}$ covers only a very small fraction of the total energy required by the system. Geothermal energy is only marginal, potentially depletable energy source without carbon emissions. It is found only in specific regions and the technology that it is required to produce energy from geothermic areas is in many cases cost inefficient.

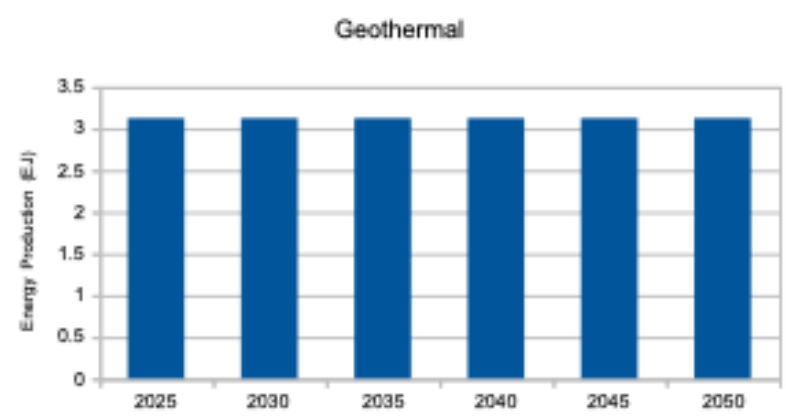

Figure 5: Geothermal Energy Production across the EU.

On the same pattern, biomass across the EU is not expected to have substantial energetic contribution (Fig. 6). It is expected to slightly increase up to the point to cover around only 1EJ of total energy production. This minor contribution can be attributed to the fact that biomass for energy production collides with land use for food production. As well as, keeping large forest areas offers substantial carbon emissions reductions and public health advantages. This is what also the authors of this publication suggest as the best approach towards societal sustainability. Minor biomass energy production could be achieved from the waste products of agricultural production, that could be not be used otherwise.

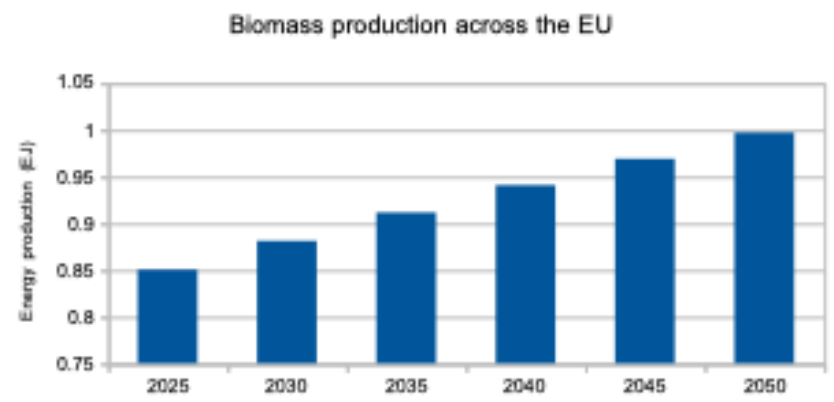

Figure 6: Biomass Energy Production across the EU.

Nuclear energy production will continue to play an important role for the European system (Fig. 7). In the current scenario it will double up to 2050. Several countries across the globe are starting new nuclear programs for energy production including Saudi Arabia. Others, like China build now a handful of new plants. They understand that along with the renewables, nuclear is a promising pathway for carbon neutralization. The European nuclear fleet could be updated to be even more safe and further expanded.

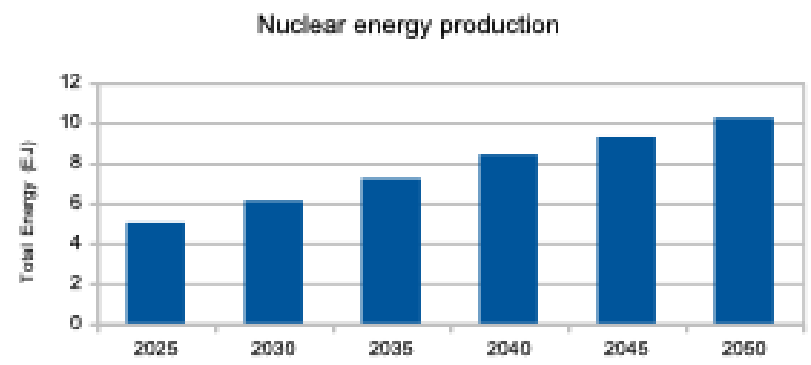

Figure 7: Nuclear Production across the EU.

\subsection{Hydrogen contribution}

In the current scenario, hydrogen is used in part as a tool to facilitate the decommissioning of the existing infrastructure. The European system is widely supported by gas and oil pipelines to transfer energy to the customers [9]. According to authors point of view, in a carbon neutral society, the electricity network that is more efficient in transferring energy 
from renewables will be used instead of pipelines. However, the existing investments could be transitionally used to transfer carbon neutral hydrogen produced from renewables and other environmentally friendly energy sources. As presented in Fig. 8, hydrogen consumption will double in the immediately following years but then it will remain relatively stable.

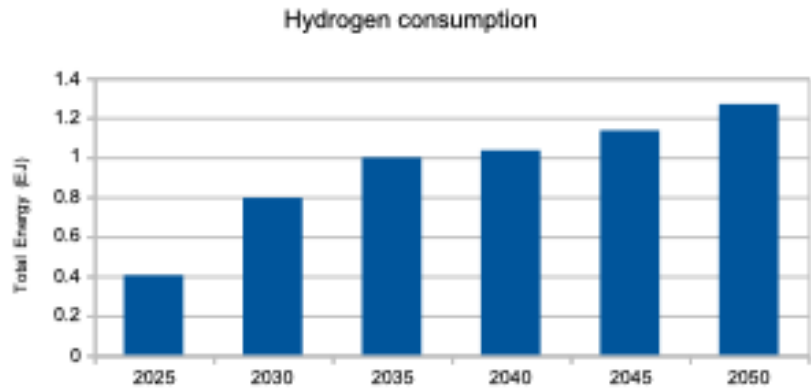

Figure 8: Hydrogen consumption across the EU.

\subsection{Carbon Capture and Storage}

Carbon storage is not yet a proven technology. Several pilot projects for storing carbon dioxide have demonstrated the applicability of concept's theoretical foundation. However, they lack the scale to be universally applied. Also, their costs may be high. For example, the Terrell carbon capture and storage plant in Texas, US is able to capture 0.4 to $0.5 \mathrm{MtC}$ per year [11]. On global level at least 800 projects of this capacity are required to fulfil the requirements of this scenario. Given the technological pluralism of CCS technologies, such a goal up to 2050 could be feasible even for comparatively small-scale projects. The problem of high costs is expected to be compensated by the increasing value of carbon emissions. Several carbon emissions trading schemes, including EU ETS [12], show increasing price trends that are not going to change in the future.

If CCS will be cost effective, it will expand the life cycle of existing and newly build fossil fuel plants and will eventually facilitate the carbon neutral EU transition. In this analysis, it has been assumed that carbon storage will have an important contribution to the system. Fig. 9 shows that from 2030 to 2050 , CCS will be almost 8 times more, being able to capture $400 \mathrm{MtC}$ per calendar year. Would CCS be able to capture $100 \mathrm{MtC}$ per year, the carbon emission neutrality would have been achieved.

\subsection{Numerical interpretation of the results}

Tables 1 and 2 present the numerical interpretation of the results presented in sections 3.1-3.4.

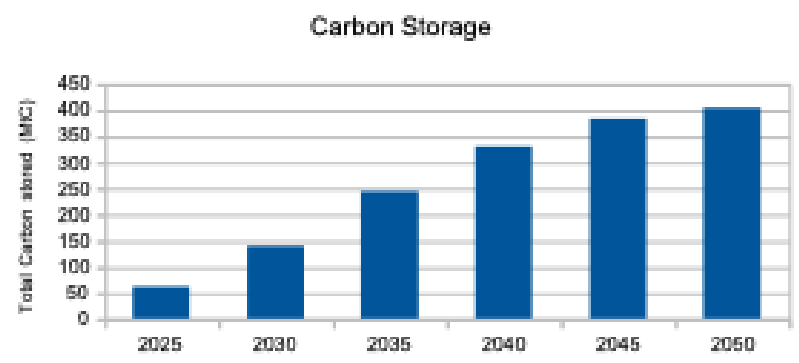

Figure 9: Carbon Storage across the EU.

All values are provided in EJ and MtC. Electricity units in the bibliography are usually given in WattHours, however for this application the use of the generic Joule instead of Watt simplifies the calculation of the equilibrium model in total. The alternative choice of transferring each value in different units could slightly increase calculation efforts and consequently is avoided.

Table 1: Calculated values from 2025 to 2035.

\begin{tabular}{|l|l|l|l|l|}
\hline & Units & \multicolumn{1}{|c|}{$\mathbf{2 0 2 5}$} & $\mathbf{2 0 3 0}$ & $\mathbf{2 0 3 5}$ \\
\hline Onshore Wind & EJ & 1.575 & 2.423 & 3.501 \\
\hline Solar & EJ & 0.005 & 0.009 & 0.014 \\
\hline Electricity & EJ & 13.864 & 15.636 & 17.890 \\
\hline CO2 emissions & MtC & 813.240 & 644.776 & 450.158 \\
\hline Hydrogen & EJ & 0.402 & 0.794 & 0.997 \\
\hline $\begin{array}{l}\text { Carbon } \\
\text { Storage }\end{array}$ & MtC & 62.287 & 140.358 & 243.908 \\
\hline $\begin{array}{l}\text { Nuclear } \\
\text { Total Energy } \\
\text { Consumption }\end{array}$ & EJ & 13298.58 & 14414.88 & 14913.68 \\
\hline Geothermal & EJ & 3.122 & 3.122 & 3.122 \\
\hline Biomass & EJ & 0.850 & 0.881 & 0.911 \\
\hline
\end{tabular}

Table 2: Calculated values from 2040 to 2050.

\begin{tabular}{|l|l|l|l|l|}
\hline & Units & $\mathbf{2 0 4 0}$ & $\mathbf{2 0 4 5}$ & $\mathbf{2 0 5 0}$ \\
\hline Onshore Wind & EJ & 4.289 & 5.334 & 6.293 \\
\hline Solar & EJ & 0.022 & 0.032 & 0.044 \\
\hline Electricity & EJ & 20.272 & 22.532 & 24.760 \\
\hline CO2 emissions & MtC & 288.077 & 173.600 & 106.697 \\
\hline Hydrogen & EJ & 1.033 & 1.134 & 1.266 \\
\hline $\begin{array}{l}\text { Carbon } \\
\text { Storage }\end{array}$ & MtC & 329.781 & 384.126 & 404.123 \\
\hline $\begin{array}{l}\text { Nuclear } \\
\text { Total Energy } \\
\text { Consumption }\end{array}$ & EJ & 8.410 & 9.290 & 10.257 \\
\hline Geothermal & EJ & 3.122 & 3.122 & 3.122 \\
\hline Biomass & EJ & 0.941 & 0.969 & 0.997 \\
\hline
\end{tabular}




\section{Conclusions}

This work presents an energetic scenario that could potentially meet Green Deal strategy requirement for achieving carbon neutrality at the European continent. This scenario does not substantially depart from the existing patterns of increasingly using renewables (wind, solar, geothermal, biomass and nuclear) to achieve the goal. However, it also investigates the possibility of transitioning from gas to electricity only using hydrogen storage, carbon storage and capture technologies. The current findings show that there is at least one energetic solution that to a certain degree, meets Green Deal strategic objectives. It has to be clarified that in this case carbon emissions are not absolutely equal to zero but very low compared to the current situation.

\section{Acknowledgment:}

The authors acknowledge support for this work from the Special Account for Research of ASPETE through the funding program "Strengthening research of ASPETE faculty members".

The calculation resources for this research were provided by Okeanos high performance cloud computing [6].

The authors would like to thank Tamar Levi for her ideas in developing this manuscript.

\section{References:}

[1] The European Green Deal, https://ec.europa.eu/info/strategy/priorities2019-2024/european-green-deal, [Accessed April 2020].

[2] S. Kim, J. Edmonds, J. Lurz, S. J. Smith and M. Wise, The ObjECTS Framework for Integrated Assessment: Hybrid Modeling of Transportation, The Energy Journal, International Association for Energy Economics, Vol. 0(Special I), 2006, pp. 63-92.

[3] Joint Global Change Research Institute (JGCRI), Global Change Assessment Model (GCAM), [Online]. Available: http://jgcri.github.io/gcam-doc/. [Accessed April 2017].

[4] S. Lazarou, L. Ekonomou and A. Dagoumas, Correlation between Representative Concentration Pathways and Paris Agreement, International Journal of Renewable Energy Research, Vol. 8, No. 2, pp. 929-940, 2018.

[5] Harvard Dataverse, 2017. [Online]. Available: http://dx.doi.org/10.7910/DVN/UFLX1G.

[6] Okeanos high performance cloud computing, Greek Research and Technology Network
(GRNET), 2018. [Online]. Available: https://okeanos-global.grnet.gr/.

[7] S. Lazarou, C. A. Christodoulou and V. Vita, Global Change Assessment Model (GCAM) Considerations of the Primary Sources Energy Mix for an Energetic Scenario that Could Meet Paris Agreement, $54^{\text {th }}$ International Universities Power Engineering Conference (UPEC), Bucharest, Romania, 2019, (DOI) 10.1109/UPEC.2019.8893507.

[8] A. Nieto, V. Vita, L. Ekonomou and N. E. Mastorakis, Economic Analysis of Energy Storage System Integration with a Grid Connected Intermittent Power Plant, for Power Quality Purposes, WSEAS Transactions on Power Systems, Vol. 11, 2016, pp. 65-71.

[9] S. Lazarou, V. Vita, M. Diamantaki, D. Karanikolou-Karra, G. Fragoyiannis, S. Makridis and L Ekonomou, A Simulated Roadmap of Hydrogen Technology Contribution to Climate Change Mitigation Based on Representative Concentration Pathways Considerations, Energy Science \& Engineering, Vol. 6, No. 3, (DOI) 10.1002/ese3.194, 2018, pp. 116-125.

[10] C. Polydoros and V. Vita, Design of an Offshore Wind Farm: Connection to the Main Electrical Grid, Proceedings of the $11^{\text {th }}$ Electrical Engineering Faculty Conference (BulEF), Varna, Bulgaria, (DOI) 10.1109/BulEF48056.2019.9030737, 2019.

[11] Terrell Natural Gas Processing Plant (formerly Val Verde Natural Gas Plants) - Global Carbon Capture and Storage Institute. http://www.globalccsinstitute.com/projects/valverde-natural-gas-plants.

[12] EU Emissions Trading System (EU ETS). https://ec.europa.eu/clima/policies/ets [Accessed April 2017].

\section{Creative Commons Attribution License 4.0 (Attribution 4.0 International, CC BY 4.0)}

This article is published under the terms of the Creative Commons Attribution License 4.0 https://creativecommons.org/licenses/by/4.0/deed.en US 